\title{
Office building deep energy retrofit: life cycle cost benefit analyses using cash flow analysis and multiple benefits on project level
}

\author{
Jan W. Bleyl 1 - Markus Bareit • Miguel A. Casas - Souran Chatterjee $\cdot$ Johan Coolen • \\ Albert Hulshoff • Rüdiger Lohse • Sarah Mitchell • Mark Robertson • \\ Diana Ürge-Vorsatz
}

Received: 30 October 2017 / Accepted: 18 June 2018 / Published online: 21 July 2018

(C) The Author(s) 2018

\begin{abstract}
Deep energy retrofit (DER) of the existing building stock is a meaningful strategy to reduce fossil fuel consumption and $\mathrm{CO}_{2}$ emissions. However, the investment volumes required to undertake DER are enormous. In Europe, cumulative demand for DER is estimated at close to 1000 billion EUR until 2050. Public expenditures and political measures can help to stimulate and guide DER, but substantial private investments are required to achieve significant results. In this paper, we analyze the economic and financial
\end{abstract}

J. W. Bleyl $(\bowtie)$

Energetic Solutions, Lendkai 29, 8020 Graz, Austria

e-mail: EnergeticSolutions@email.de

M. Bareit

Swiss Federal Office of Energy (SFOE), 3003 Bern, Switzerland e-mail: markus.bareit@bfe.admin.ch

\section{A. Casas}

Energinvest, 107 rue Joseph Coosemansstraat, 1030 Brussels,

Belgium

e-mail: mcasas@energinvest.be

S. Chatterjee · D. Ürge-Vorsatz

Centre for Climate Change and Sustainable Energy Policy, Central

European University, Nádor utca 9, Budapest, Hungary

\author{
S. Chatterjee \\ e-mail: Chatterjee_Souran@phd.ceu.edu \\ D. Ürge-Vorsatz \\ e-mail: vorsatzd@ceu.edu
}

implications for renovating an office building to the "Passive House" standard. This is achieved by applying a dynamic Life Cycle Cost \& Benefit Analysis (LCCBA) to model the cash flows (CF). The model also includes an appraisal of debt and equity financing implications, and a multi-parameter sensitivity analysis to analyze impacts of input parameter deviations. In the second part of the paper, we use the "multiple project benefits" (MPB) concept to identify project-based cobenefits of DER (with a focus on productivity), to make

\footnotetext{
J. Coolen

Factor4, Lange Winkelhaakstraat 26, 2060 Antwerpen, Belgium e-mail: johan.coolen@factor4.eu
}
A. Hulshoff
AHB Consultancy, Griffensteijnseplein 40, 3703 BG Zeist, The Netherlands
e-mail: albert.hulshoff@ahb-consultsancy.nl
R. Lohse
Klimaschutz- und Energieagentur Baden-Württemberg,
Kaiserstraße 94a, 76133 Karlsruhe, Germany
e-mail: ruediger.lohse@kea-bw.de
S. Mitchell · M. Robertson
EfficiencyOne, 230 Brownlow Ave., Suite 300, Dartmouth, Nova Scotia B3B 0G5, Canada
S. Mitchell
e-mail: smitchell@efficiencyns.ca
M. Robertson
e-mail: mrobertson@efficiencyns.ca 
the business case more attractive. Results show that the DER project cash flow over a 25 -year period achieves a 21-year dynamic payback with an IRR of below $2 \%$. Levelized Cost of Heat Savings is 100 EUR/MWh with a 70\% capital expenditure and 15\% interest cost share. The Loan Life Cover Ratio comes out to 1.2. To make the business case more attractive, pecuniary MPBs identified are increased rents, real estate values, (employee) productivity, maintenance costs, and $\mathrm{CO}_{2}$ savings, in addition to societal benefits. Compared to simpler economic modeling, the dynamic LCCBA cash flow model provides solid grounds not only for DER business case analysis, project structuring, and financial engineering, but also for policy design. CFs from future energy cost savings alone are often insufficient in convincing investors. However, they can co-finance DER investments substantially. Consideration of project level MPBs can offer meaningful monetary contributions, and also help to identify strategic allies for project implementation; however, the "split incentive" dilemma requires differentiation between tenants and different types of investors. Furthermore, the approach supports policy-makers to develop policy measures needed to achieve 2050 goals.

Keywords Building deep energy retrofit - Cost benefit analyses $\cdot$ Cash flow analyses $\cdot$ Multiple benefit .

Business case

\section{Introduction}

The energy-saving potential in the building sector is enormous. Deep energy retrofit (DER) ${ }^{1}$ of the existing building stock would be a meaningful strategy to reduce fossil fuel consumption and transition toward a decarbonized energy system. However, at current building renovation rates of below $1 \%$ per annum, it appears to be largely under-developed. To pursue this strategy on a level capable of achieving climate protection goals, enormous investment volumes would be needed. For example, in Europe, cumulative investment demand for DER until 2050 is estimated at 937 billion EUR (present value) in the Buildings Performance Institute Europe's

\footnotetext{
${ }^{1}$ As defined by IEA Annex 61, a Deep Energy Retrofit is a major building renovation project in which site energy use intensity, including plug loads, has been reduced by at least $50 \%$ from the prerenovation baseline.
}

“Deep" scenario (BPIE 2011). This amount cannot be financed from public sectors alone and will require substantial private sector engagement. A similar situation can be assumed for many other parts of the "developed" world.

If the assumption for the necessity of more private sector involvement is true, a thorough understanding of the economic and financial implications of DER project cash flows (CF) is needed as a basis for further discussion and strategy development with relevant stakeholders. Likewise, it is important to communicate and present investment opportunities in a business language that potential investors are familiar with. Technical performance parameters of energy efficiency (EE) measures, or static economic analysis, are less meaningful and unlikely to attract interest and understanding from financial decision makers. Therefore, this requires a dynamic CF modeling and economic and financial key performance indicators (KPI) including sensitivity and risk analysis of DER. The goal of the first part of the paper is to shed light on these questions.

Given the long payback time of more than 20 years for most DER cases, the economic rationale often cannot be justified by $\mathrm{CF}$ from future energy cost savings alone, nor could these CFs convince potential investors. By applying the concept of the "Multiple Benefits of Energy Efficiency" (IEA 2014) to DER projects or programs, we are attempting to capture additional benefits, revenues, and drivers on the microeconomic level. The purpose is to find approaches on how to monetize multiple project benefits to make the business case more attractive. This is the focus of the second part of the paper.

The application of multiple benefits (MBs) for building DER is supported by other authors as well. Among others, the Buildings Performance Institute Europe states that "limiting the discussion about energy efficient buildings only to climate change considerations would ignore the many additional benefits which are created through the retrofitting of the European building stock. The revitalization of urban quarters, improved comfort levels and quality of living and working spaces, helping people out of fuel poverty and creating long-term employment are just some of the many positive effects" (BPIE 2011; Renovate-Europe 2016). Generally, in the real estate sector, human health and comfort are gradually getting more to the forefront of building practices and attention. For examples the "WELL Building Standard" (IWBI 2017) is an expression of this development. 
However, there is still too little discussion on providing quantifications for the MBs of DER, in particular on the microeconomic level. The Rocky Mountain Institute provides some guidelines on "How to calculate and present deep retrofit value." These guidelines state "These types of retrofits reduce operating costs and are able to improve the satisfaction and health of occupants", highlighting multiple stakeholders and beneficiaries of DER, and its benefits beyond just energy cost savings (RMI 2015). Woodroof et al. report that "a high percentage of facility managers experienced ... reduced maintenance material costs as a result of energy conservation" and "calculated these benefits to be worth approximately $31 \%$ of additional value beyond the direct energy dollar savings" (Woodroof et al. 2012). Other authors focus more on technical implications of DER and the need for an integrated design approach during building design phase in order to achieve nearly zero energy buildings (nZEB), mainly for new buildings (Integrated Design 2017). As a common theme, authors highlight the actuality of MBs of EE measures and their multiple beneficiaries on individual, institutional, and societal levels. At the same time, approaches for quantification and integration, particularly on the project level, are still rare.

This paper presents work that is original content and has not been published before. After the methodology section, we present a DER office building case study. This is followed by an analysis of relevant MBs in the context of DER, with a special focus on work productivity, and focusing on quantification approaches on the project level to allow integration into the business case; the authors refer to those MBs which are relevant to project stakeholders as multiple project benefits (MPBs). The modeling does not focus on topics such as tax, public debt, or policy implications - the latter are addressed in the conclusion section only. In addition to approaches to MB quantification, results are discussed from the perspectives of potential investors, building users, and financiers.

\section{Methods}

DER case study and dynamic Life Cycle Cost Benefit Analysis

For the first part of the paper, we use a case study methodology (Yin 2014) to assess economic and financial implications of a DER project (mainly building envelope insulation to the "Passive House" standard). This bottom-up approach is based on a real life DER project from Germany. The capital expenditures (CAPEX) of the DER are based on actual construction costs. ${ }^{2}$ The incremental cost approach used (sometimes also referred to as "differential" or "anyway" cost) excludes the general, non-energy-related costs of the building renovation.

The economic and financial Life Cycle Cost Benefit Analysis (LCCBA) is built on a dynamic cash flow model of the DER case study, with a focus on the perspectives of potential investors and financing institutions. For this purpose, the projected income and expense CFs are modeled over an entire project cycle of 25 years, with the degree of detail of a pre-feasibility study. Economic KPIs are the internal rate of return (IRR), the net present value (NPV), and a dynamic amortization period, separately for the project (P-CF) and the equity cash flow (E-CF). Furthermore, the "Levelized Cost of Energy" (LCoE) (IEA/NEA 2015) concept is applied to calculate levelized cost of energy savings as a simple comparison variable to different energy supply and savings variants. On the financing side, the influence of typical debt ratios of $70 \%$ on the remaining equity $\mathrm{CF}$, as well as liquidity, is examined using the financial KPIs "Cash Flow Available for Debt Service" (CFADS) and the "Loan Life Coverage Ratio" (LLCR).

The analysis also includes a multi-parameter sensitivity analysis of the IRR and NPV with respect to deviations of relevant input parameters, e.g., CAPEX, OPEX, price development of the energy cost baseline, and project duration, and to determine threshold values for MB contributions. Throughout the paper, all monetary figures exclude value added tax (VAT), and tax effects are not considered.

Inclusion of multiple project benefits

Energy-saving projects or programs often produce benefits beyond reduced energy consumption and peak demand, which contribute to the objectives of organizations implementing the projects and can have significant added value for those making investment decisions (SEEAction 2012). These benefits are not always

\footnotetext{
${ }^{2}$ Deviating from the actual construction costs, so-called "cost-efficient passive house components" for windows and doors were used for the case study (B. Kaufmann, personal communication, Sept. 23, 2015).
} 
understood or quantified. However, when energysaving projects are only marginally attractive to investors or lack support from other stakeholders, a thorough understanding of the benefits and internalization of key benefits in the economic analysis can make the difference between projects moving ahead or being overlooked. Since the net effect of these impacts is usually beneficial, we use the term multiple benefits to describe them, as used by the International Energy Agency (IEA 2014); however, the terms non-energy benefits and non-energy impacts are also common.

A growing body of research recommends the systematic assessment of MBs for both individual energy efficiency projects and for analysis of policies or programs encouraging EE (e.g., Ürge-Vorsatz et al. 2015, 2016). A common approach for evaluation of policies or programs is to classify MBs according to their primary beneficiary: Participant (individual or business implementing the project), Utility (electric utility or fuel delivery companies that deliver energy to the Participant), or Society (Lazar and Colburn 2013). For analysis of project-specific MBs as described in this paper, the investigation of identified Utility and Society MBs was not important, as they were deemed irrelevant to the project business case. For benefits on the microeconomic or project level, which directly impact project stakeholders, we suggest use of the term multiple project benefit (MPB).

An important distinction was made between MPBs that applied to different stakeholders within the Participant category. Figure 1 presents an adapted benefit classification scheme for individual projects that includes common scenarios of Participant facility ownership: "Occupant/Owner" (one who owns and occupies the property), "Lessor/Owner" (one who owns and leases the property), and "Property Developer" (one who owns the property but intends to sell after upgrades are completed). These labels represent possible stakeholder scenarios and each one would not necessarily exist for every project.

In addition to identification and classification of MPBs, any individual benefit may be relatively easy or difficult to quantify in a useful manner. Methods and accuracy of quantification vary widely between benefits, and depend on the desired accuracy of financial estimates. Decisions regarding policy or public investment in energy efficiency programs often estimate MBs as a numerical multiplier applied to estimated energy savings; a higher degree of accuracy is typically sought when evaluating MPBs at the project level. Those MPBs that cannot be quantified can still be discussed with stakeholders as they often have some bearing on investment decisions and can help identify new potential investors.

Further to Fig. 1, which isolates those beneficiaries that are relevant to the business case, Fig. 2 adds a dimension of the relative difficulty in quantifying each benefit. Project proponents may find the use of such a grid helpful in early project development. The two dimensions of the grid are "relevance to the business case" and "difficulty of quantification"; the result being four quadrants into which each identified benefit is

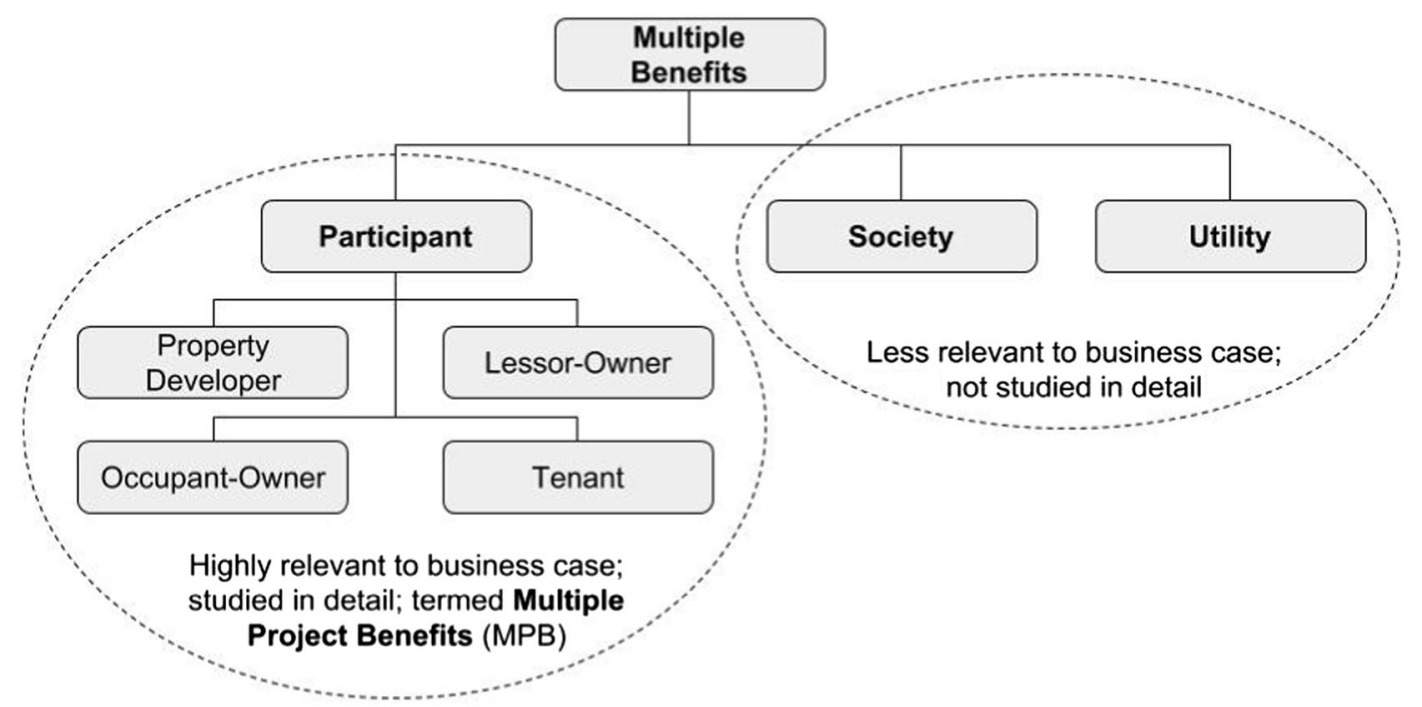

Fig. 1 Classifications of multiple benefits according to primary beneficiary 
Fig. 2 Multiple benefits classification grid

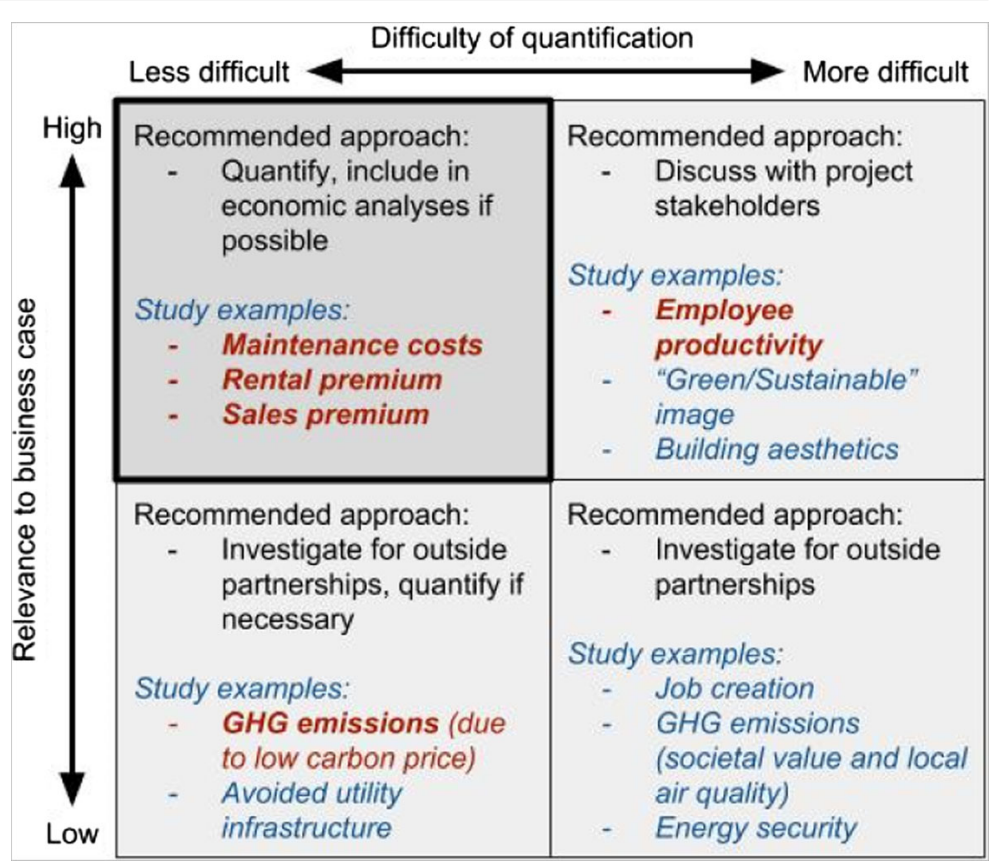

placed, which then determines the recommended approach for further investigation of that MPB. The upper half are generally the MPBs, and the upper left quadrant are those MPBs which are included in the business case. For the case study project introduced in Section "DER case study and LCCBA model", a five-step methodology was followed to include MPBs:

1. List all potentially significant benefits for the project

2. Classify each benefit according to the primary beneficiary: Participant, Utility, or Society, as well as any important sub-classifications. Estimate the difficulty in quantifying each benefit. Plot each benefit on the grid in Fig. 2

3. Select quantification methods and quantify chosen MPBs in either financial or non-financial terms

4. Incorporate significant financial results into economic analysis

5. Consider unquantified and quantified non-financial MPBs as additional arguments to support the project.

For the case study described in this paper, quantified individual Participant benefits are investigated in sections "Higher work productivity, Higher revenues from rent or sales, Valuing avoided greenhouse gas emissions, and Maintenance cost savings". Section "Benefits not accounted for in the business case" lists unquantified Participant benefits and benefits for Utility and Society, which were not investigated in detail. Several benefits were quantified according to various methods that are currently available, and are described in the respective subsections, with those that could be readily expressed in financial terms then included in project economic analysis.

\section{DER case study and LCCBA model}

In this section, a DER office building case study is analyzed with a dynamic Life Cycle Cost \& Benefit Analysis (LCCBA) to model project and equity cash flows. The goal is to better understand economic and financial implications of DER projects and to appraise debt and equity financing implications. This model shall serve as a basis for business case analysis, MPB evaluation, and discussion of results for different stakeholders.

The case study concerns a 1960s era office building, with $1680 \mathrm{~m}^{2}$ of heated area, situated in southern Germany. The building was renovated to the "Passive House" (PH) standard in the years 2010-2011. The EE renovation included ceiling, wall, and basement insulation, window and doors replacement (with costefficient Passive House components), improvements to airtightness, ventilation, and heating systems, and a 
lighting retrofit. The investment costs of the DER amounted to 0.56 million EUR or $330 \mathrm{EUR} / \mathrm{m}^{2}{ }^{3}$.

The energy costs before the renovation (baseline) were 45,000 EUR/year (36,500 EUR/year for gas and 8500 EUR for electricity). After DER, gas costs are reduced by $88 \%$; electricity cost savings are limited to a $17 \%$ reduction due to the additional ventilation systems. The energy and all other price increases are assumed to be on average $1.5 \%$ year. In the business model, from year 6 onwards, building users participate in the savings with $3 \%$. Maintenance cost savings are not factored into the business case; however, additional maintenance cost for ventilation systems are accounted for. Costs for a general overhaul of the heating system in year 15 , as well as regular lamp replacements, are also included.

Financing of the investment is modeled with a mix of $75 \%$ debt capital (20-year term with an effective interest rate of $2.52 \%$ ) and $25 \%$ equity with a yield expectation of $4.5 \%$ for the Weighted Average Cost of Capital (WACC) calculation. No subsidies were accounted for to avoid distorting the results. CAPEX is refinanced from the future savings cash flow over a 25 -year project term.

Results of the LCCBA CF analysis are displayed in Fig. 3. The analysis of the project $\mathrm{CF}$ over 25 years results in accumulated energy cost savings of EUR 810,000 resulting from an investment of EUR 550,000 and maintenance costs of EUR 120,000. The result is a positive P-CF of EUR 145,000 with an internal rate of return of just $1.9 \%$, a negative NPV of EUR $-62,000$, and a dynamic payback period of 21 years. For the equity $\mathrm{CF}$, an IRR of $0.8 \%$ results with a payback period of 24 years; discounted at $4.5 \%$, the NPV of the E-CF is -77,000 EUR (Fig. 3).

The sensitivity analysis in Fig. 4 shows the influence of a percentage change of selected input parameters on the project IRR. The model provides a similar analysis for the equity IRR and NPV, which is not presented here.

Investment costs, followed by saving revenues, project duration, and baseline price development, are the most sensitive to relative changes of input parameters. For a break-even with the WACC $(\mathrm{NPV}=0)$, the

\footnotetext{
${ }^{3}$ According to the incremental cost approach, this figure excludes general, non-energetically relevant costs of the building renovation of $167 \mathrm{EUR} / \mathrm{m}^{2}$ for building site equipment, scaffolding, plastering, facade, fire, and noise protection.
}

CAPEX would need to be decreased by $11 \%$ or the savings increased by $10 \%$ or a through a $13 \%$ longer project duration.

The DER business case results will be discussed after the next section on MPBs in building DER.

\section{Multiple project benefits of building DER}

Energy efficiency measures such as the above example of a DER business case induce "multiple project benefits" beyond energy cost savings. In this section, we identify, structure, and - where possible - monetize relevant MPBs for different stakeholder groups. The primary goal is to identify sources of additional revenues for DER business cases. In a broader picture, cobeneficiaries, who might have a vested interest to become strategic allies for DER programs, shall be identified. MPBs are grouped in (1) financially quantified, with a special focus on labor productivity (sections "Higher work productivity, Higher revenues from rent or sales, Valuing avoided greenhouse gas emissions, and Maintenance cost savings") and (2) additional benefits not accounted for in the business case (section "Benefits not accounted for in the business case").

\section{Higher work productivity}

Earlier studies for energy efficiency programs suggested that productivity gains could be among the most significant benefits of building-related energy efficiency investments (Wargocki et al. 1999; Seppänen et al. 1999; Wargocki et al. 2000; Fisk, 2000; Miller et al. 2009). Urge-Vorsatz et al. 2016 paper reviewed monetized multiple benefits of building energy efficiency measures and confirmed that in the few studies having a comprehensive account of non-energy multiple benefits, productivity improvements score high. ${ }^{4}$

Recent work demonstrates that breathing air in buildings is responsible for a very significant loss of life and disability even in Europe (Asikainen et al. 2016). Many studies show how indoor air quality can cause several diseases such as asthma, cold, flu, allergy, and even cardiovascular diseases and cancer (Fisk 2000; Fisk

\footnotetext{
${ }^{4}$ In order to understand and measure the phenomena in depth, the H2020 project COMBI aims at elaborating systematic methodologies to quantify these benefits, consistently with other multiple impacts (COMBI 2015). For more details about multiple benefit methodology, please visit COMBI website (https://combi-project.eu/).
} 
Fig. 3 Net project, equity, and debt cash flows (annual and cumulative)

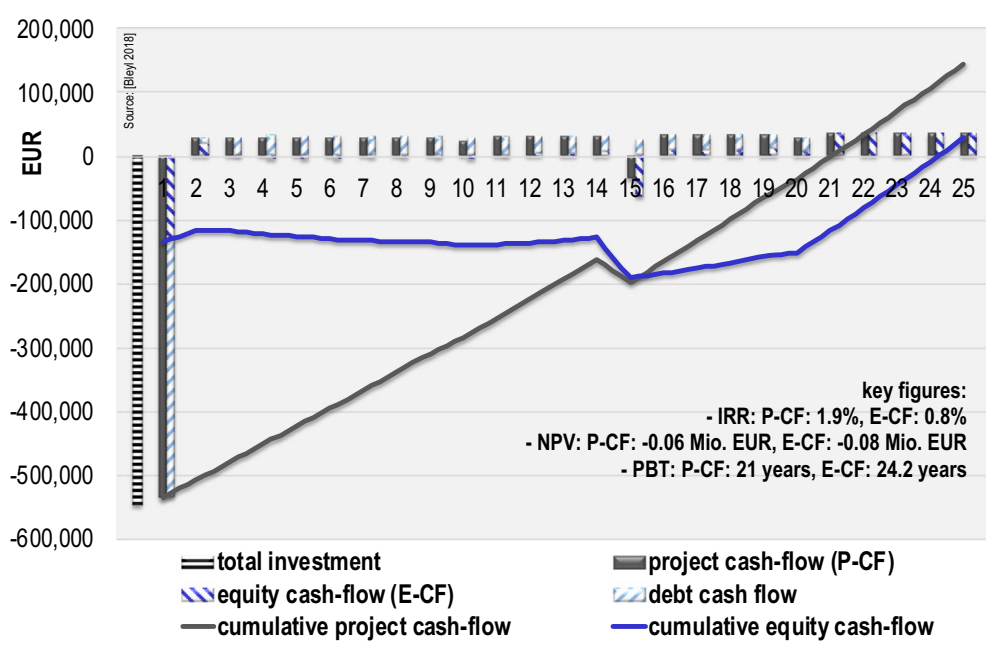

have heat recovery ventilation) reduce air quality-related disability, and therefore improve productivity.

In this section, we describe work productivity indicators and approaches on how these benefits can be quantified. We measure work productivity by considering different aspects of labor efficiency increases resulting from DER programs. We focus on two key aspects of labor productivity: (1) active days gained by reduction of sick days, healthy life years and (2) workforce performance improvements as a result of increased

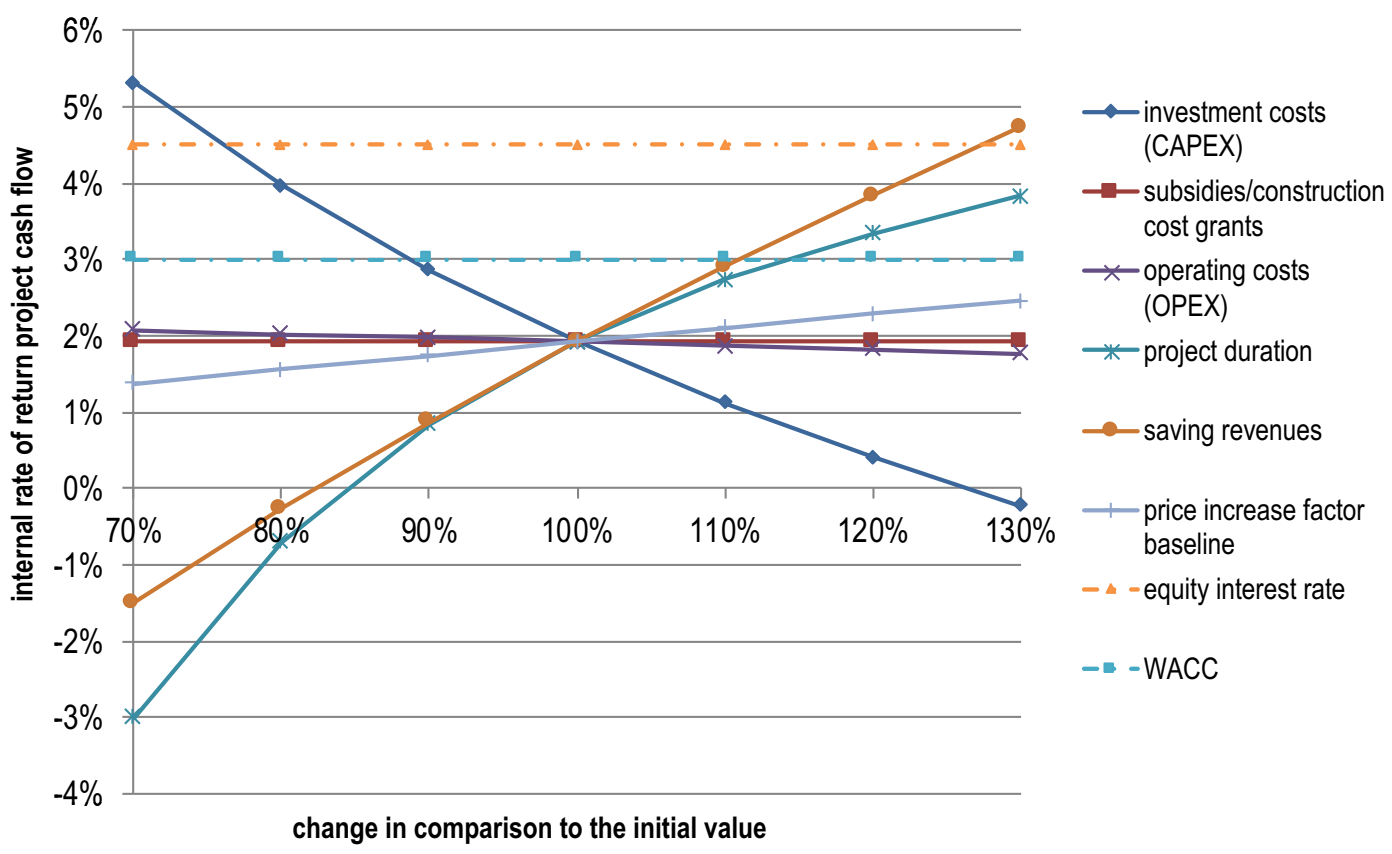

Source: [Bleyl 2018]

Fig. 4 Sensitivity of project IRR to relative change of input parameters 
comfort and other improved conditions. Each of these indicators are introduced in the following subsections.

\section{Active days}

Active days consist of two main aspects: Sick days and healthy life year loss. Sick day is a linear combination of absenteeism (absent from work due to building-related illness) and presenteeism (Caverley et al. 2007), where presenteeism can be defined as working with illness or working despite being ill (Mattke et al. 2007). Each of these aspects of active days are discussed in the below section:

1. Sick days estimate the morbidity of working population, i.e., the number of days of suffering from building-related illness (BRI) by the working population. Absenteeism and presenteeism are the two aspects which measure the morbidity due to BRI.

- Absenteeism: absenteeism due to illness is a rising concern for both the employees and as well as the employers. Many work days get wasted due to BRI (Fisk and Rosenfeld 1997; Jones 1999; Arnetz, et al. 2003). Most of the studies estimated the cost of indoor exposure by measuring the absenteeism and health care expenditure, but among these two, only absenteeism indicates productivity loss (Fisk 2002; Chapman, et al. 2009). A 2000 study by Fisk estimated that the cost of annual lost days due to sick building syndrome in the USA would be as high as $\$ 34$ billion (Fisk 2000).

Absenteeism days have been used as an indicator for many other types of research as well such as to evaluate health promotion programs, to evaluate vaccination programs etc. (Golaszewski et al. 1992; Milton et al. 2000). In these studies, absenteeism reduction is used as an indicator for productivity. One of the key reasons behind this poor indoor air quality is inadequate air exchange rates inside the building and lack of filtration system (Asikainen et al. 2016). Installing an efficient heating ventilation and air conditioning (HVAC) system with filtration, which is typically installed in a DER, can reduce up to $58 \%$ of global burden of disease at EU-26 level (Hänninen and Asikainen 2013). Studies suggest that with proper ventilation rate, i.e., more than
$12 \mathrm{~L} / \mathrm{s}$ per person can reduce sick days by $1.2-$ 1.9 days per person per year (Milton et al. 2000; Carrer et al. 2012). Thus, this 1.2 to 1.9 days can be considered as productivity gain per person/ year due to energy efficiency action.

Deep renovation of building envelope ensures maximum air tightness, which prevents outdoor air pollutant infiltration and mechanical ventilation system stimulates the indoor air exchange rate by replacing indoor air (polluted) with filtered outdoor air which provides a healthier indoor environment (Wargocki et al. 2002).

- Presenteeism due to building-related illness is an indicator which has not been discussed yet in any study. However, the loss of productivity, presenteeism is not small. According to the Institute for Employment 2016 report, in Europe, the average days of presenteeism are 3.1 in a year per person (Garrow 2016). Lamb et al. (2006) estimated the productivity loss of $3.2 \mathrm{~h}$ due to presenteeism in an 8-h-work day. Furthermore, presenteeism days especially, presenteeism due to illness may increase the risk of having an ill health because inadequate recuperation may lead to further acute health problems (McEwen 1998).

2. Healthy life year: many of the building-related illness affects mortality and mortality cannot be measured through sick days. Thus, the disabilityadjusted life year (DALY) indicator is used to estimate both mortality as well as morbidity along with sick days indicator to provide a complete understanding of the severity of indoor exposure. Absenteeism and presenteeism mostly measure acute diseases whereas there are many chronic diseases caused by the poor indoor environment. For instance, 23\% lung cancer is caused due to indoor exposure (Hänninen and Asikainen 2013). Diseases such as lung cancer and cardiovascular disease caused by indoor exposure have an impact on life span (i.e., these diseases do not only affect working days but also affect life expectancy).

\section{Workforce performance}

Workforce performance can be defined as labor input by the workforce per unit of time. Workforce defines as an 
accumulation of all the employees at the workplace. We estimate workforce performance gains mainly through the quantity of labor input, but poor indoor air quality can also affect the quality of work (Wargocki et al. 2000). Several case studies show how indoor air quality and thermal comfort can influence a person's productivity (Seppänen et al. 1999; Wargocki, et al. 2000; Singh 2005; Helsen and Coolen 2013; Coolen et al. 2012). By working in deep retrofitted type buildings, employees have better work performance compared to working in non-retrofitted buildings (Wargocki et al. 2000; Singh 2005; Singh et al. 2010). This performance improvement not only benefits the employees but it also benefits the employer by improving labor input efficiency, which will be quantified as a MPB of DER.

There are mainly three reasons behind this improvement in performance which are discussed below:

- Reducing mental disorder: improvement in indoor air quality helps in reducing mental stress which results in more labor input. For instance, a Singh et al. study (2010) shows that after shifting into an energy efficient building, employers can gain an additional 2.02 work hours per person per year because workers were feeling less mental stress. These additional working hours can certainly be considered as productivity gain per person. One of the possible reason behind feeling less mental stress could be that a worker is constantly exposed to the fresh air which replenishes attention and boosts up the energy to work (Singh et al. 2010; Ryan et al. 2010).

- Improvement in mental health conditions: thermal comfort helps to improve a person's concentration ability which improves work performance (Wargocki et al. 2000). A Wargocki et al. study (2000) estimated a $1.7 \%$ improvement in productivity (mainly quality of work) after controlling the room temperature within $21-25^{\circ} \mathrm{C}$. In mechanical ventilation systems, an adequate temperature is always maintained throughout the day with the help of a temperature control system (Eskom 2015).

- Better concentration ability: concentration ability may get hindered by certain symptoms such as eye irritation (eye tears and eye blinking) and skin irritation which affects the work performance (Mølhave et al. 1986). Mold and fungi growth can be stopped by improving the building shell and by implementing stringent air filtration (Singh 2005). In the deep retrofit type buildings with HVAC, system ensure constant fresh air intake which prevents further mold and fungi growth and during building shell improvement the existing molds are being removed as a part of retrofitting process (Bonetta et al. 2010).

These three effects may also have a combined effect on work performance. Finding the data to evaluate workforce performance indicators is still a big challenge. Few studies measure performance enhancement at the office buildings by doing a control group survey (Wargocki et al. 2000; Singh et al. 2010). These control group results vary from study to study and are not directly comparable because of different monetary units mostly without mentioning the physical value. Thus, authors have suggested to use "Comfortmeter" to evaluate workforce performance enhancement after DER, which is introduced in the next subsection.

\section{Measuring workforce performance through "Comfortmeter"}

Comfortmeter ${ }^{5}$ is an online survey tool that objectifies the subjective comfort experience of building users. The survey polls building users on 6 aspects of comfort (thermal comfort, air quality, acoustics, lighting, individual control, and office environment \& cleanliness), on the work performance impact ("productivity increase" called in Comfortmeter reports) of their working environment and on personal characteristics (age, gender, stress level, job satisfaction, ....). It calculates comfort scores of the building which are benchmarked against similar buildings in the Comfortmeter database, and it proposes measures to improve the scores and ranks them according to their expected impact on productivity.

In case of a successful DER of a low performing building, the overall comfort score of the building is expected to increase between 2 and 4\% (Coolen et al. 2012). This increase of overall comfort score will be generated mainly by the improved thermal comfort, indoor air quality, lighting, and acoustics in the building. The econometric

\footnotetext{
5 "Comfortmeter" is the result of a collaboration between international authorities involved in efficient, sustainable, and performance-oriented office buildings such as Factor4 and six renowned European universities, including KU Leuven and TU Braunschweig. The tool is used in several European R\&D-projects such as GeoTabs (Helsen and Coolen 2013; Coolen et al. 2012) and Quantum (www.quantum-project.eu). The Comfortmeter database is constantly growing and contained in October 2017 the data of 3600 building users of 116 office buildings spread over 11 countries.
} 
model of the Comfortmeter shows that a $1 \%$ increase in overall comfort score results in an average $0.19 \%$ work performance increase (Helsen and Coolen 2013). Thus, the DER would generate a work performance increase between 0.38 and $0.76 \%$ [( 2 to 4$) \times 0.19 \%]$.

For the benefit assessment, the work performance of an average Belgian employee of 75,000 EUR/employee (i.e., salary cost, non-salary cost (ICT, facilities, ...), and profit margin) and an average overall office space of $27.5 \mathrm{~m}^{2}$ per employee (or 0.0364 employees per $\mathrm{m}^{2}$ ) is taken into account. Thus, the DER would generate a workforce performance increase of 10.4 to $20.8 € / \mathrm{m}^{2}$ [(0.38 to $\left.0.76 \%\right) \times$ $75,000 \times 0.0364]$, which can be included in the business case as a MPB quantification.

Similar results are also confirmed by the Dutch Literature survey "Kentallen binnenmilieu and productiviteit" (Boerstra and Van Dijken 2015). The survey gives an overview of empirical evidence of the correlation between productivity and the four elements of indoor climatethermal comfort (temperature), air quality, acoustics, and light.

Higher revenues from rent or sales

There is growing evidence from studies that sustainable building features like energy efficiency, and its MPBs, have a positive impact on building values (Eichholtz et al. 2010; Kok and Jennen 2011; Chegut et al. 2011 and 2013; Fuerst and McAllister 2008; Reichardt et al. 2012; Laurenceau 2013; Hyland et al. 2012). The studies compare certified green buildings with non-certified buildings and find a positive correlation with rental rates and the transaction prices of commercial property (corrected for non-energy efficiency-related characteristics such as location, age, and size). According to these sources, investing in energy efficiency, and thus obtaining green or sustainable building certification, translates to higher rent ranging from below $4 \%$ up to $21 \%$. Numbers for higher market valuations (transaction or sales prices) range from below $10 \%$ to up to $30 \%$ (USA) or $26 \%$ (Europe). ${ }^{6}$ In other

\footnotetext{
${ }^{6}$ These price premiums are for "sustainable buildings" whereby the "energy efficient" component is one aspect of the sustainability besides accessibility, water and waste management, indoor quality, and building management. Other intangibles such as market conditions, market size, increase of global quality of buildings, the mentioned employee productivity increase, and green image also play a role in price premiums.
}

words, businesses and individuals are willing to pay a rental or sales premium for "green" property.

These premiums are not only a matter of green or sustainable building certifications supporting increased rents or property values but also a matter of lowefficiency buildings losing rent and sales value - the latter more and more ingloriously referred to as "brown discount," as demonstrated by Kok and Jennen (2012). They claim that the aggregated effect of these opposite effects is large and also indicate that it is bound to increase following stricter environmental regulation and changing tenant preferences.

However, energy efficiency is just one of several "green" building features. For the purpose of this research, we propose to conservatively allocate $25 \%$ of the premiums to EE. For the rental premium, this results in a range of $1-5.3 \%$ of an assumed monthly net office rent of $10 \mathrm{EUR} / \mathrm{m}^{2}$. For the sales premium, a range of 2.5$6.5 \%$ of a sales price of $4000 \mathrm{EUR} / \mathrm{m}^{2}$ is assumed, which gives us a sales premium range of 100 to 260 $€ / \mathrm{m}^{2}$. Furthermore, it is important to consider that benefits are capitalized by different stakeholders in the commercial property market such as tenants and buyers.

The ongoing and future mandatory adoption of energy performance certifications or energy labels by the market will increase the availability and transparency of energy consumption data in buildings, and thus improve the effectiveness of the certifications and labels. For tenants and buyers, it will then be much easier to take energy efficiency into their financial models when making commercial property decisions.

\section{Valuing avoided greenhouse gas emissions}

Higher energy productivity leads to a reduction in final fuel and electricity demand, and respective greenhouse gas (GHG) emissions. These reductions can contribute to climate change mitigation. Besides its social benefits, reducing GHG emissions could lead to additional financial advantages for project proponents, depending on the country's climate cost internalization policies. This is the case if building owners can generate certificates out of the GHG reductions that can be traded in an emission trading scheme, or by saving GHG levies on fossil fuels.

The European Union (EU) has established the world's largest Emissions Trading System (EU ETS). Approximately 11,000 European businesses and aircraft operators (with flights within Europe) participate in the EU ETS. It is a market-based instrument that 
internalizes the external cost of GHG emissions with the goal of reducing emissions cost-effectively while achieving its climate objectives (European Commission 2017). An emission allowance offers the right to emit 1 ton of $\mathrm{CO}_{2}$. Currently, there is a surplus of emission allowances leading to low costs. In the period April 2017 to April 2018, the average price for one emission allowance was around EUR $8 .^{7}$ It remains to be seen whether new EU climate goals, based on the Paris agreement, can lead to stronger policy measures and a substantial increase of emission allowance prices in the near future.

Besides an emission trading system, some countries impose a GHG levy on heating fuels. For example, Switzerland introduced such a levy and currently charges 84 Swiss Francs (approx. EUR 79) per ton of $\mathrm{CO}_{2}{ }^{8}$. This is a significantly higher value than the current EU ETS prices.

Applied to the DER case study, 318 MWh of natural gas and $6 \mathrm{MWh}$ of electricity are saved, which results in GHG savings of about $80 \mathrm{t}$ /year of $\mathrm{CO}_{2 \mathrm{eq}} \cdot{ }^{9}$ Valued at current EU ETS prices, this results in savings of about 400 EUR/year. Valued with the Swiss GHG levy on heating fuels, savings of about $6300 \mathrm{EUR} /$ year result. In both cases, transaction costs to realize GHG revenues are not accounted for. ${ }^{10}$

\section{Maintenance cost savings}

Building DER also encompasses retrofit of existing, and often aged, building technologies. Besides energy cost savings, this leads to a net reduction of maintenance cost and/or replacement investment for the building owner (Woodroof et al. 2012), which can be factored into the business case. This approach is applied in energy savings contracts with energy service companies (ESCos).

DER will typically decrease maintenance costs due to the fact that a newer installation typically requires less

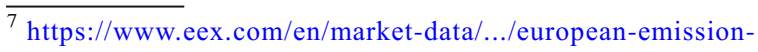
allowances-auction\#!/ (visited 20.04.2018)

${ }^{8}$ https://www.bafu.admin.ch/bafu/en/home/topics/climate/infospecialists/climate-policy/co2-levy.html (visited 20.04.2018)

${ }^{9} \mathrm{CO}_{2 \text { eq }}$ emission factors: natural gas $250 \mathrm{~kg} / \mathrm{MWh}$, electricity $700 \mathrm{~kg} /$ MWh (Source: GEMIS http://iinas.org/gemis-de.html, visited 13.03.2017)

${ }^{10}$ The resulting revenue of a reduced $\mathrm{CO}_{2}$ levy for an investor or landlord also depends on the cost sharing between landlord and tenant. Often the fuel costs are paid by the tenant who would profit from the investments of the landlord, which leads to the well-known landlordtenant dilemma or principal-agent problem.
}

maintenance. In the case of performance-based outsourcing of maintenance in the DER project (using the NEN 2767, see below), the contractor will choose installations with lower maintenance costs and optimize the maintenance process. However, this positive cost saving effect could be partially offset due to increased maintenance costs that result from a more complex and maintenance-intensive building, generated by the DER.

In our DER case study, two effects on maintenance cost were observed: (1) a cost reduction of $2.1 \mathrm{EUR} / \mathrm{m}^{2}$ for the existing systems and (2) additional maintenance cost of $0.9 \mathrm{EUR} / \mathrm{m}^{2}$ due to the added ventilation systems (which have already been accounted for in the case study calculation in section "DER case study and LCCBA model"). In the Belgian office building case study, maintenance cost savings were found to be 3 EUR $/ \mathrm{m}^{2}$ (Coolen et al. 2012).

These numbers are based on the assumption that in the reference scenario, the maintenance in the building is conducted in a standard approach and that the corresponding maintenance costs are made.

An interesting metric to measure maintenance levels of technical systems was identified in the Netherlands. The Dutch maintenance standard NEN 2767 advises on a uniform way to inspect and assess the construction and installation of technical infrastructures and to assess their technical condition by assigning so-called "condition scores." This allows quantification of maintenance levels in an objective way and can be applied as a metric.

\section{Benefits not accounted for in the business case}

In addition to the benefits discussed in sections "Higher work productivity, Higher revenues from rent or sales, Valuing avoided greenhouse gas emissions, and Maintenance cost savings", there are several other Participant benefits that are challenging to quantify, but still enhance the value of the project. The following Participant benefits were identified, but were not quantified or included in the economic analysis. They were, however, discussed and considered by project stakeholders prior to making investment decisions.

The unquantified Participant MPBs identified for the case study were as follows:

- Sustainable image and environmental designations

- Asbestos removal

- Building esthetics 
Benefits to Utility and Society were not deemed to have significant influence on the business case for this project and were not investigated in detail. Their identification is still an important exercise, as these benefits may have the potential to engage additional funding partners with niche interests (e.g., the prospect of job creation could potentially be used to obtain funding from local development authorities). If this were the case, it would make sense for that benefit to be classified as a Participant benefit.

The Utility and Society MBs identified for the case study were as follows:

- Boost of local economy and job creation

- Reduced greenhouse gas emissions

- Improved local air quality resulting from reduced fossil fuel combustion and associated reduced health system costs

- Reduced fossil fuel import and improved national energy security

- Avoided electric and natural gas utility system infrastructure costs

Because of the project approach, these benefits to utilities and society were not pursued further in this paper.

\section{Discussion}

LCCBA model and DER business case study based on energy cost savings only

For the first part of the discussion, results of the dynamic LCCBA DER model based on energy cost saving CF only are discussed.

Despite positive cumulated CFs of the case study, the business case appears not to be attractive to investors. Appraised solely by the economic and financial KPIs of DER energy cost savings CF, it will be difficult to attract private sector investments. This is due to negative NPVs, long payback periods, low IRRs of P-CF and $\mathrm{E}-\mathrm{CF}$, project risks, and liquidity shortfalls in early project years.

Also, the Levelized Cost of Heat Savings of 100 EUR/MWh, which can be used as a comparison with alternative heat generation costs, does not indicate an economic saving potential when compared to typical average $^{11}$ cost of heat supply. In conclusion, building DER is typically not a stand-alone business case if based on future energy cost savings alone, even with a longterm investment horizon of 25 years.

The above KPIs are not sufficiently reflected in standard economic appraisals like simple payback or annuity calculations (often with residual book values for individual assets, which typically consider averaged values instead of CFs and do not reflect "time value of money"). The differences in approach explain why assessment of economic viability of DER with different economic models may come to dissenting results. For long-term DER investment and financing decisions, as well as enabling policy design, a dynamic life cycle cost and benefits appraisal is needed, as proposed with the LCCBA model. Dynamic modeling is also required, because of the high sensitivity ${ }^{12}$ of price and cost development scenarios (c.f. Fig. 4), which underlines the risks of compounded interest effects due to long project durations.

From a different angle, future energy cost saving CF may be viewed as a highly potent source for cofinancing DER investments. As can be seen from the sensitivity analysis of the case study, $88 \%$ of CAPEX could be refinanced if an NPV of 0 is chosen as a goal of the P-CF. The opportunity to substantially co-finance DER investments with future savings CFs deserves much more attention. This would require a multi-year project cycle perspective across CAPEX and OPEX budgets, and adjustment of respective accounting guidelines and procedures, which in return would require enabling policy guidelines and their implementation. To reduce CAPEX, imputable investment cost for DER can be deducted by so-called "anyway" cost of building maintenance (or other cost items) through a "differential cost approach,"

Opportunity cost of delaying investments in saving opportunities is substantial $(28,000 \mathrm{EUR} /$ year for the case study), which is often not discussed nor factored into the timing of EE investment decisions. Instead of waiting for CAPEX budgets to be available, it would often be cheaper to pay for debt capital or other thirdparty financiers like ESCos and be able to invest and profit from savings sooner. Unfortunately, this way of

\footnotetext{
${ }^{11}$ It is even less attractive, when compared to the marginal cost of heat supply, which is the more appropriate comparison.

${ }^{12}$ Impact of absolute changes of energy price development is even more sensitive, e.g., $\pm 1 \%$ result in an NPV of +3000 EUR, or 120,000 EUR respectively
} 
thinking is not common practice for many public or private sector building owners.

The DER life cycle cost structure is characterized by high capital and low operating cost portions: the share of CAPEX is $70 \%$ of total project cost, with interest accounting for another $15 \%$, and just $15 \%$ for OPEX. This cost structure is an indicator of the societal benefits of DER, as there is a substitution of OPEX on (imported) fossil fuels with CAPEX on (local) construction companies and labor (c.f. IEA 2014). Furthermore, the currently low interest rate favors comprehensive energy efficiency investments in buildings.

MPB classification, quantification, and relevance to different stakeholders

Before discussing integration of MPBs into the DER business case, a few considerations on classification and relevance of MPBs to different stakeholders are presented.

While the method of classification into four quadrants helps determine which MPBs should be quantified (see Fig. 2), it does not prescribe methods of quantification. As the industry shifts to a greater focus on the inclusion of MPBs in project economics, it is expected that new tools will be developed to aid in quantification of benefits in different applications. Industry experts should stay aware of these developments and actively seek new and better methods of quantification.

In our case study, the top half of the grid (MPBs that are "highly relevant to the business case") mainly include MPBs that benefit the Participant. When evaluating "relevance to the business case" for a particular $\mathrm{MPB}$, it may be helpful to develop an order-ofmagnitude estimate of its impact relative to project costs and other benefits before investing time on more formal quantification.

As described in section "Benefits not accounted for in the business case", even those societal MPBs that initially seem to have little relevance to the project could potentially be investigated for outside funding opportunities or other types of strategic support. Therefore, the authors encourage tabulation and classification of all potential MPBs as a first step to their meaningful inclusion in project development.

In terms of laying the procedural groundwork for attainment of future savings, engineers and economists should work to move MPBs from right to left on the grid (i.e., develop new methods of quantification) while policy-makers should work to move MPBs from bottom to top on the grid (i.e., create financial conditions that value a wider range of impacts). As a policy example, raising the price on carbon emissions would gradually move "GHG emissions" from the bottom-left to the topleft quadrant by internalizing these social costs into the business case. In our case study, the financial value of avoided emissions was easily quantified and directly benefits the Participant, but was relatively insignificant in the context of total project costs and savings, so it was placed in the bottom-left quadrant.

Another benefit that may result from pursuing MPBs is a potential to engage with strategic partners or other funding sources that may be concerned with these benefits (or risks). Important drivers for the building refurbishment of the case study from section "DER case study and LCCBA model" were noise protection from a busy street, ventilation, and fire protection due to changes in use and structure of the building. In the case of asbestos removal, the local health department would have a vested interest in providing support to the building owner to ensure effective and safe removal of the asbestos, and could potentially offer both financial and labor contributions to the project. Similarly, strategic allies may be identified for MPBs benefitting Utility or Society. For example, reduction of peak electricity loads may help the local distribution utility defer costly growth-related upgrades to distribution infrastructure. This cooperation perspective acknowledges the fact that energy cost savings from DER are often not high enough to build a stand-alone business case, which is proposed by other authors as well (BPIE 2011; RMI 2015). In many cases, DER will need strategic partners, with a vested interest in its MPBs, in order to move forward.

Approaching work productivity quantification

Section "Higher work productivity" provides a concrete guideline to measure work productivity of DER program in office buildings. An Urge-Vorstaz et al. study (2016) pointed out that it is not easy to quantify multiple benefits as it involves several issues such as proper identification of benefits, systematic methodologies to quantify, and data availability. This section contributes to the knowledge pool of productivity measurement of DER (and possibly other) programs by identifying the extent of the effect of DER on work productivity and 
also by proposing indicators to quantify these DER specific work productivity aspects.

Functionally, the change in productivity can be expressed as follows:

$\Delta$ Productivity

$=f($ active days, workforce performance $)$

where $\Delta$ Productivity is the change in labor output after DER in office buildings. Furthermore, active days can be functionally expressed as follows:

Active days $=f($ sick days, healthy life year $)$

where sick days is a combination of absenteeism and presenteeism.

Thus, any change in these components will have an effect on overall labor productivity. For example, a greater number of active days and healthy life years would imply more labor output, hence an increase in productivity.

In this paper, MBs are monetized at the project level and from investor's as well as tenant's perspectives (c.f. 5.4). This implies that monetization of benefits should not include any societal value. If societal value of any benefits is included in cost-effectiveness analysis where the CBA is conducted to see participants' gains/losses on project level, then it would lead to overestimation of result.

In addition, many of the aspects of a benefit cannot be quantified due to lack of appropriate data. For instance, the active day indicator could not be incorporated in our estimation due to the data unavailability. Monetization values of active days especially absenteeisms in existing literature (for example see Fisk 2002 study) include societal benefits. That is why in Table 1 section "Integration of monetized MPBs into the DER business case and its relevance to different Stakeholders", the productivity figure only includes the results of workforce performance ignoring the values of active day.

As can be seen in the next section, the effect of inclusion of workforce performance in our model is quite significant. However, we must note that the Comfortmeter also incorporates the comfort-related performance gain, and as discussed in section "Workforce Performance", there are several aspects (specifically related to mental well-being) to which performance can be enhanced. Comfortmeter does not incorporate any mental disorder improvement or concentration ability-related performance gains. Thus, even after inclusion of results related to work performance, our result shows a conservative value since there are many aspects which cannot be included due to data unavailability.

Integration of monetized MPBs into the DER business case and its relevance to different stakeholders

The goal of this subsection is to discuss values of different MPBs identified in section "Multiple Project Benefits of Building DER" to the DER business case and their accountability to different groups of stakeholders.

To recap, financially quantified MPBs identified in the context of building DER are (numbers refer to Table 1): (1) work productivity increase; (2a) rental income increase; (2b) building sales price increase; (3) $\mathrm{CO}_{2}$ emission reduction; (4) maintenance cost savings and (5a) energy cost savings during project term (already considered in base case scenario in section "DER case study and LCCBA model"); and (5b) additional energy cost savings during technical lifetime (beyond project term).

A positive correlation of these MPBs to stakeholder benefits can be assumed to be consensus, however, quantification methods maybe subject to further discussion (Woodroof et al. 2012). The ranges of monetary values of the MPBs presented are a first attempt, to the best of our knowledge, based on case studies and literature (not on any broader empirical bases). In order to find a comparable metric to which readers can relate to more easily, MPB value ranges in Table 1 are presented in $\left[\mathrm{EUR} / \mathrm{m}^{2}\right]$, both as annual values $\left[\mathrm{EUR} / \mathrm{m}^{2} /\right.$ year] as well as present values ${ }^{13}$ (PV) of future savings cash flows over a 25 -year period in $\left[\mathrm{EUR} / \mathrm{m}^{2}\right]$.

The valuation of MPBs in Table 1 reveals relevant orders of magnitude of MPBs compared to energy cost savings, with the exception of $\mathrm{CO}_{2}$ savings valued at current ETS prices. In particular, work productivity is in a similar range as energy cost savings. Additionally, it should be pointed out that quantifications for work productivity increases represent a conservative approach. From its two main indicators, just work performance improvements could be monetized through "Comfortmeter," whereas the first indicator active days,

\footnotetext{
${ }^{13}$ For the PV calculation, a 25-year project term with a WACC of $3 \%$ as discount rate and $1.5 \%$ year price increase was applied (equal to the case study analysis in section "DER case study and LCCBA model").
} 
Table 1. Monetary values of multiple project benefits of DER (in $\left[E U R / \mathrm{m}^{2}\right]$ - annually and present values of project cash flows ${ }^{14}$ )

\begin{tabular}{|c|c|c|c|c|}
\hline \multirow[t]{2}{*}{ Multiple project benefits of DER } & \multirow[t]{2}{*}{ Range } & \multicolumn{3}{|l|}{ Valuation } \\
\hline & & {$\left[\mathrm{EUR} /\left(\mathrm{m}^{2} * \mathrm{y}\right)\right]$} & & PV: $\left[E U R / m^{2}\right]$ \\
\hline \multirow[t]{2}{*}{ 1. Work productivity increase $(0.57-1.14 \%)$} & Lower & 10,4 & & 219 \\
\hline & Upper & 20,8 & & 439 \\
\hline \multirow[t]{2}{*}{ 2a. Rental income increase $(1-5.3 \%)$} & Lower & 1,2 & & 25 \\
\hline & Upper & 6,4 & & 134 \\
\hline \multirow[t]{2}{*}{ 2b. Building sales price increase $(2.5-6.5 \%)$} & Lower & & 100 & \\
\hline & Upper & & 260 & \\
\hline \multirow[t]{2}{*}{ 3. $\mathrm{CO}_{2}$ savings $(6-79 \mathrm{EUR} / \mathrm{t})$} & Lower & 0,3 & & 6 \\
\hline & Upper & 3,8 & & 79 \\
\hline \multirow[t]{2}{*}{ 4. Maintenance cost savings (2.1-3 EUR/m2/y) } & Lower & 2,1 & & 44 \\
\hline & Upper & 3,0 & & 63 \\
\hline \multirow[t]{2}{*}{ 5a. Energy cost savings project term ( 25 years) } & Lower & 16,8 & & 354 \\
\hline & Upper & 16,8 & & 354 \\
\hline \multirow[t]{2}{*}{ 5b. Add. energy cost savings over techn. lifetime ( 40 years) } & Lower & 16,8 & & 157 \\
\hline & Upper & 16,8 & & 157 \\
\hline
\end{tabular}

e.g., through absenteeism and presenteeism could not be monetized yet.

The total MPBs value contribution needed to reach a minimum economic threshold level $(\mathrm{P}-\mathrm{CF}=0)$ is $12 \%$ of the CAPEX (as can also be seen from the sensitivity analysis in Fig. 4), which translates to $1.8 \mathrm{EUR} / \mathrm{m}^{2} / \mathrm{y}$, or an PV of about $38 \mathrm{EUR} / \mathrm{m}^{2}$ (respectively 65,000 EUR for the entire building). Compared to a plausible range of MPBs contributions as outlined in Table 1, this appears to be in a reasonable, and even surpassable, range. These results generally support the approach to factor MPB values into DER business cases and should make DER more attractive to investors.

Table 2 reveals substantially different total benefit values for different groups of beneficiaries. This underlines the necessity to differentiate between different beneficiaries also for MPB analysis (c.f. section "MPB classification, quantification, and relevance to different stakeholders"). Occupant-owners have the highest total benefit values of the different types of building owners, but tenants also have substantial net benefits.

When comparing differential DER investments of 330 $\mathrm{EUR} / \mathrm{m}^{2}$ to the MPB values, the occupant-owner's benefits are greater than the cost by a factor of between 2.4 and 3.3; for tenants, values are between 1.7 and 2.2. This is a clear indication for a potentially interesting business case. By example of the occupant-owner case, the project IRR would go up to $8.8 \%$ and equity IRR to $21.4 \%$, if the total of the lower MPB values in Table 1 could be realized over the 25 -year project period (excluding $5 \mathrm{~b}$ ).

On the other hand, the lessor-owners appear to have very small benefits, because of low rental premiums (even smaller than sales premiums). The same applies to property developers, where price premiums for DER buildings are not sufficiently reflected in market prices, probably due to a lack of LCCBA assessments on the buyer side of the market. In both cases, the "split incentive" 14 dilemma is apparent, because investors do not capitalize from OPEX reductions of building occupants. From this perspective, it would be justified to allow building owners in regulated markets to charge higher rents in return for investments in tenant's OPEX savings. In this context, guaranteed OPEX reductions, as applied in performance-based energy services, could be helpful. Based on the MPBs values, tenants should also have a vested interest to rent DER renovated "green" buildings. Alternatively, long-term tenants have grounds to invest their own money, provided they are aware of the benefits.

In any case, investors' appetite for DER will still require low debt capital interest rates (as is currently the case), a long-term perspective of $20+$ years investment horizon, and rather low expectations on its equity

\footnotetext{
${ }^{14}$ For a further discussion of the split incentive problem, and the development of possible solutions, we refer to the H2020-project GuarantEE (http://guarantee-project.eu/be/)
} 
Table 2. Accountability of multiple project benefits of DER (in EUR $/ \mathrm{m}^{2}$ ) to different groups of beneficiaries ${ }^{\mathrm{a}}$

\begin{tabular}{|c|c|c|c|c|c|c|}
\hline \multirow[b]{3}{*}{ Multiple project benefits of DER } & \multirow[b]{3}{*}{ Range } & \multicolumn{5}{|l|}{ Beneficiaries } \\
\hline & & \multirow{2}{*}{$\begin{array}{l}\text { Valuation } \\
\mathrm{PV} \text { in }\left[\mathrm{EUR} / \mathrm{m}^{2}\right]\end{array}$} & \multicolumn{4}{|c|}{ Different owner perspectives } \\
\hline & & & Property develop & Occupant-owner & Lessor-owner & Tenant \\
\hline \multirow[t]{2}{*}{ 1. Work productivity increase } & Lower & 219 & - & 219 & - & 219 \\
\hline & Upper & 439 & & 439 & & 439 \\
\hline \multirow[t]{2}{*}{ 2a. Rental income increase } & Lower & 25 & - & - & 25 & -25 \\
\hline & Upper & 134 & & & 134 & -134 \\
\hline \multirow[t]{2}{*}{ 2b. Building sales price increase } & Lower & 100 & 100 & {$[100]$} & {$[100]$} & - \\
\hline & Upper & 260 & 260 & {$[260]$} & {$[260]$} & \\
\hline \multirow[t]{2}{*}{ 3. $\mathrm{CO} 2$ savings } & Lower & 6 & - & 6 & - & 6 \\
\hline & Upper & 79 & & 79 & & 79 \\
\hline \multirow[t]{2}{*}{ 4. Maintenance cost savings } & Lower & 44 & - & 44 & 44 & - \\
\hline & Upper & 63 & & 63 & 63 & \\
\hline \multirow[t]{2}{*}{ 5a. Energy cost savings project } & Lower & 354 & - & 354 & - & 354 \\
\hline & Upper & 354 & & 354 & & 354 \\
\hline \multirow[t]{2}{*}{ 5b. Add. energy cost savings over techn. lifetime } & Lower & 157 & - & 157 & - & {$[157]$} \\
\hline & Upper & 157 & & 157 & & {$[157]$} \\
\hline \multirow[t]{2}{*}{ Totals } & Lower & & 100 & 780 & 69 & 554 \\
\hline & Upper & & 260 & 1092 & 197 & 738 \\
\hline
\end{tabular}

a Except for the "property developer," the values in $2 \mathrm{~b}$. for the building sales price are in parentheses and not colnsidered in the totals, because they depend on the time of sale; similar logic for $5 b$ "tenant" values

return. In return, investments must be structured with a very low risk profile (because of low returns). For the business model, this will require a stable savings $\mathrm{CF}$ scenario with low technical risks and simplified $M \& V$ (c.f Bleyl et al. 2014) for the verification of the savings $\mathrm{CF}$, which is generally compatible with DER cases. Furthermore, business cases must be structured, guaranteed (e.g., through performance-based energy services), and reported in a standardized format, and aggregated in larger volumes to reduce transaction costs. ${ }^{15}$

\section{Conclusions}

In summary, the following conclusions can be drawn with regard to our research questions:

1. Results of the dynamic LCCBA cash flow model provide solid grounds not only for DER business

\footnotetext{
${ }^{15}$ For approaches to standardization, certification of bankable energy efficiency projects you may refer to the Investor Confidence Project (ICP) (http://www.eeperformance.org/)
}

case analysis, project structuring, and financial engineering, but also for policy design (as compared to static payback analysis or other types of simpler economic modeling). Equally important, it can bridge the language gap between decision makers and other stakeholders, particularly with financial backgrounds, such as potential DER investors.

2. For DER projects, CF from future energy cost savings alone is typically not enough to convince private sector investors. Even with a long-term investment horizon of more than 20 years, DER is not a stand-alone business case. However, savings CF can be structured to co-finance DER investments substantially by up to $85 \%$. This approach may open up new perspectives toward project implementation with rather small co-financing needed.

3. In addition to societal benefits, DERs can generate tangible and quantifiable benefits on the project level beyond energy cost savings, such as higher rents and real estate values, maintenance cost and $\mathrm{CO}_{2}$ savings, and higher work productivity. Despite the challenges of exact quantification, these MPBs can offer meaningful contributions to the 
attractiveness of a business case. Moreover they can help to identify strategic allies for DER programs and project development. However, the well-known "split incentive" dilemma requires differentiation between tenants and different types of investors. Use of a simple classification grid such as that in Fig. 2 can help determine appropriate treatment of individual benefits.

4. Currently, low interest rates provide a huge opportunity for capital-intensive programs. However, for a meaningful DER implementation strategy including private sector financial engagement, policymakers would need to define clear and mandatory goals (e.g., minimum renovation rates), remove barriers to private sector involvement (e.g., revise EUROSTAT accounting rules for public debt of which the latest Guidance Note dated 19 September 2017 can be considered a step in the right direction), and increase investment security and structure policy frameworks that allow "internalization" of MPB values into the business case (e.g., creating economic incentives for a wider range of impacts, taking measures to raise EU ETS prices, allowing investors to capitalize from OPEX reductions through higher rents) in order to achieve 2050 climate goals. Another important issue to foster investor appetites is the streamlining of due diligence processes as requested by the Energy Efficiency Financial Institutions Group (EEFIG) ${ }^{16}$ and implemented by the Investor Confidence Project or the Small Enterprise Assistance Fund (SEAF). ${ }^{17}$ Also, reducing CF risks by agreeing on simplified $\mathrm{M} \& \mathrm{~V}$ procedures would decrease investor risk perspectives.

The approach to combining energy cost savings with the added values of MPBs to enhance DER business cases appears to be promising. Nevertheless, work remains to be done: (1) an encouraging and stable DER policy framework is needed; (2) concertation with potential long-term and "green" investors (e.g., institutional investors like pension funds or the like) and project developers; and (3) enhancement of the MPB quantification approaches which could also be incorporated in performancebased services. The proposed classification approach for MPBs may be helpful to structure and

\footnotetext{
$\overline{16} \mathrm{http}: / /$ www.eefig.com

${ }^{17} \mathrm{http}: / /$ seaf.com
}

analyze future MPBs research and project implementation. In any case, not only other DER projects but also policy programs can build on the methodological approach of this paper to assess project cash flows and incorporate MPB.

Acknowledgements This work was carried out in the framework of the International Energy Agency's Demand Side Management Technology Collaboration Program Task 16 (www. ieadsm.org) in cooperation with EBC's Annex 61 (http://ieaannex61.org/). Annex 61 and Task 16 bring together experts on performance-based energy services (ESCo) and DER from countries around the world, who join forces to advance ESP business models and markets. Your questions or remarks are very welcome. You can reach the authors through EnergeticSolutions@email.de.

\section{Compliance with ethical standards}

Conflict of interest These authors declare that they have no conflict of interest.

Open Access This article is distributed under the terms of the Creative Commons Attribution 4.0 International License (http:// creativecommons.org/licenses/by/4.0/), which permits unrestricted use, distribution, and reproduction in any medium, provided you give appropriate credit to the original author(s) and the source, provide a link to the Creative Commons license, and indicate if changes were made.

\section{References\}

Arnetz, B. B., Sjögren, B., Rydéhn, B., \& Meisel, R. (2003). Early workplace intervention for employees with musculoskeletalrelated absenteeism: a prospective controlled intervention study. Journal of Occupational and Environmental Medicine, 45(5), 499-506. https://doi.org/10.1097/01. jom.0000063628.37065.45.

Asikainen, A., Carrer, P., Kephalopoulos, S., Fernandes, E. D., Wargocki, P., \& Hänninen, O. (2016). Reducing burden of disease from residential indoor air exposures in Europe (HEALTHVENT project). Environmental Health, 15(S1). https://doi.org/10.1186/s12940-016-0101-8.

Bleyl, J. W., Bareit, M. \& Sattler, P. Simplified measurement \& verification + quality assurance instruments for energy, water and $\mathrm{CO}_{2}$ savings - methodologies and examples. ECEEE 2014 Industrial Summer Study (pp. 133-142).

Boerstra A. \& Van Dijken F. (2015) Kentallen binnenmilieu \& productiviteit ten behoeve van de EET value case tool (Dutch literature study of international scientific studies on the relation between inside air quality and productivity/ absenteeism).

Bonetta, S., Bonetta, S., Mosso, S., Sampò, S., \& Carraro, E. (2010). Assessment of microbiological indoor air quality in 
an Italian office building equipped with an HVAC system. Environmental monitoring and assessment, 161(1-4), 473483.

(BPIE) Buildings Performance Institute Europe (2011). Europe's buildings under the microscope: a country-by-country review of the energy performance of buildings

Carrer, P., Fanetti, A.C., Bischof, W., Hartmann, T, Kephalopouslos, S., Popov, T., Palkonnen, S., Seppänen, O., Wargocki, P. (2012). Report WP4: health and ventilation: review of the scientific literature. HealthVent Project.

Caverley, N., Cunningham, J. B., \& Macgregor, J. N. (2007). Sickness presenteeism, sickness absenteeism, and health following restructuring in a public service organization. Journal of Management Studies, 44(2), 304-319. https://doi. org/10.1111/j.1467-6486.2007.00690.x.

Chapman, R., Howden-Chapman, P., Viggers, H., Odea, D., \& Kennedy, M. (2009). Retrofitting houses with insulation: a cost-benefit analysis of a randomised community trial. Journal of Epidemiology \& Community Health, 63(4), 271277. https://doi.org/10.1136/jech.2007.070037.

Chegut, A., Eichholtz, P., Kok, N., Quigley, J.M. (2011). The value of green buildings: new evidence from the United Kingdom. ERES 2010 Proceedings

Chegut, A., Eichholtz, P., \& Kok, N. (2013). Supply, demand and the value of green buildings. Urban Studies, 51(1), 22-43. https://doi.org/10.1177/0042098013484526.

COMBI Project Consortium. (2015). Calculating and operationalising the multiple benefits of energy efficiency in Europe. Retrieved Oct. 7, 2017 from http://combiproject.eu/

Coolen, J., Klonek, F., \& Wuyts, S. (2012). Report of comfort surveys by Comfortmeter. Unpublished manuscript.

Eichholtz, P., Kok, N., \& Quigley, J. M. (2010). Doing well by doing good? Green office buildings. American Economic Review, 100(5), 2492-2509. https://doi.org/10.1257 /aer.100.5.2492.

Eskom. (2015). Heating, ventilation and air conditioning (HVAC) systems: energy-efficient usage and technologies. Eskom integrated demand management. http://www.eskom.co. $\mathrm{za} /$ sites/idm/Documents/AdvisoryServicesHVACSystemBrochure.pdf

European Commission. (2017). The EU Emissions Trading System (EU ETS). Retrieved January 26, 2017 from https://ec.europa.eu/clima/policies/ets_en

Fisk, W. J., \& Rosenfeld, A. H. (1997). Estimates of improved productivity and health from better indoor environments. Indoor Air, 7(3), 158-172. https://doi.org/10.1111/j.16000668.1997.t01-1-00002.x.

Fisk, W. J. (2000). Health and productivity gains from better indoor environments and their relationship with building energy efficiency. Annual Review of Energy and the Environment, 25(1), 537-566. https://doi.org/10.1146 /annurev.energy.25.1.537.

Fisk, W. J. (2002). How IEQ affects health, productivity. ASHRAE Journal, 44(5), 56-58.

Fuerst, F., \& Mcallister, P. M. (2008). Green noise or green value? Measuring the effects of environmental certification on office property values. SSRN Electronic Journal. https://doi. org/10.2139/ssrn.1140409.

Garrow, V. (2016). Presenteeism: a review of current thinking. Institute for Employment Studies.
Golaszewski, T., Snow, D., Lynch, W., Yen, L., \& Solomita, D. (1992). A benefit-to-cost analysis of a work-site health promotion program. Journal of Occupational Medicine, 34(12), 1164-1172.

Helsen, L., Coolen, J., e.a. (2013) Comfort experience of users in offices with and without Geotabs ('Comfortervaring in kantoren mét en zonder Geotabs'). in TVVL magazine, 05,2013

Hänninen, O., \& Asikainen, A. (2013). Efficient reduction of indoor exposures: health benefits from optimizing ventilation, filtration and indoor source controls. National Institute for Health and Welfare (Finland).

Hyland, M., Lyons, R. C., \& Lyons, S. (2012). The value of domestic building energy efficiency-evidence from Ireland. SSRN Electronic Journal. https://doi.org/10.2139 /ssrn.2096296.

Integrated Design. (2017). Integrated design: market transformation towards nearly zero energy buildings through widespread use of integrated energy design. Retrieved Jan. 16, 2017 from www.integrateddesign.eu/

(IEA) International Energy Agency. Capturing the multiple benefits of energy efficiency. (2014). Paris: OECD/IEA.

(IEA/NEA) International Energy Agency \& Nuclear Energy Agency. Projected costs of generating electricity: 2015 edition. (2015). Paris: IEA/NEA/OECD.

(IWBI) International WELL Building Institute. (2017). The WELL Building Standard. Retrieved Oct. 25, 2017 from https://www.wellcertified.com/en/explore-standard

Jones, A. (1999). Indoor air quality and health. Atmospheric Environment, 33(28), 4535-4564. https://doi.org/10.1016 /s1352-2310(99)00272-1.

Kaufmann, B. personal communication, Sept. 23, 2015

Kok, N., \& Jennen, M. (2012). The impact of energy labels and accessibility on office rents. Energy Policy, 46, 489-497. https://doi.org/10.1016/j.enpol.2012.04.015.

Kok N. \& Jennen M. (2011). The value of energy labels in the European office market. Retrieved from http://immobilierdurable.eu/images/2128_uploads/KOK_ The_Value_of_Energy_Labels_in_the_European_Office_Market.pdf

Lamb, C. E., Ratner, P. H., Johnson, C. E., Ambegaonkar, A. J., Joshi, A. V., Day, D., et al. (2006). Economic impact of workplace productivity losses due to allergic rhinitis compared with select medical conditions in the United States from an employer perspective. Current Medical Research and Opinion, 22(6), 1203-1210. https://doi.org/10.1185 /030079906x112552.

Laurenceau, S. Analyse de la Valeur Verte dans l'immobilier de bureau. (2013). Centre Scientifique et Technique du Bâtiment, Direction Economie et Sciences Humaines.

Lazar, J., \& Colburn, K. (2013). Recognizing the full value of energy efficiency. Montpelier, VT: Regulatory Assistance Project.

Mattke, S., Balakrishnan, A., Bergamo, G., \& Newberry, S. J. (2007). A review of methods to measure health-related productivity loss. American Journal of Managed Care, 13(4), 211-217.

Mcewen, B. S. (1998). Protective and damaging effects of stress mediators. New England Journal of Medicine, 338(3), 171179. https://doi.org/10.1056/nejm199801153380307. 
Miller, N., Pogue, D., Gough, Q., \& Davis, S. (2009). Green buildings and productivity. Journal of Sustainable Real Estate, 1(1), 65-89.

Milton, D. K., Glencross, P. M., \& Walters, M. D. (2000). Risk of sick leave associated with outdoor air supply rate, humidification, and occupant complaints. Indoor Air, 10(4), 212-221. https://doi.org/10.1034/j.1600-0668.2000.010004212.x.

Mølhave, L., Bach, B., \& Pedersen, O. (1986). Human reactions to low concentrations of volatile organic compounds. Environment International, 12(1-4), 167-175. https://doi. org/10.1016/0160-4120(86)90027-9.

Mudarri, D., \& Fisk, W. J. (2007). Public health and economic impact of dampness and mold. Indoor Air, 17(3), 226-235. https://doi.org/10.1111/j.1600-0668.2007.00474.x.

Reichardt, A., Fuerst, F., Rottke, N. B., \& Zietz, J. (2012). Sustainable building certification and the rent premium: a panel data approach. Journal of Real Estate Research., 34(1), 99-126.

Renovate-Europe Why is a thriving energy renovation market essential to drive the EU economy? http://renovate-europe. eu/media-centre/infographics/ accessed 16 January 2016.

(RMI) Rocky Mountain Institute. (2015). How to calculate and present deep retrofit value: a guide for investors. Boulder, Co.

Ryan, R. M., Weinstein, N., Bernstein, J., Brown, K. W., Mistretta, L., \& Gagné, M. (2010). Vitalizing effects of being outdoors and in nature. Journal of Environmental Psychology, 30(2), 159-168. https://doi.org/10.1016/j.jenvp.2009.10.009.

Seppänen, O. A., Fisk, W. J., \& Mendell, M. J. (1999). Association of ventilation rates and $\mathrm{CO} 2$ concentrations with health and other responses in commercial and institutional buildings. Indoor Air, 9(4), 226-252. https://doi.org/10.1111/j.16000668.1999.00003.x.

Singh, A., Syal, M., Grady, S. C., \& Korkmaz, S. (2010). Effects of green buildings on employee health and productivity. American Journal of Public Health, 100(9), 1665-1668. https://doi.org/10.2105/ajph.2009.180687.

Singh, J. (2005). Toxic moulds and indoor air quality. Indoor and Built Environment,14(3-4), 229-234. doi:https://doi. org/10.1177/1420326x05054015
(SEEAction) State and Local Energy Efficiency Action Network. (2012). Energy Efficiency Program Impact Evaluation Guide. Prepared by Steven R. Schiller, Schiller Consulting, Inc.

Ürge-Vorsatz, D., Kelemen, A., Gupta, M., Chatterjee, S., Egyed, M., \& Reith, A. (2015). Literature review on multiple impact quantification methodologies-D2.1 report. Budapest, Hungary: COMBI. doi: https://doi.org/10.13140 /RG.2.2.26856.26885

Ürge-Vorsatz, D., Kelemen, A., Tirado-Herrero, S., Thomas, S., Thema, J., Mzavanadze, N., et al. (2016). Measuring multiple impacts of low-carbon energy options in a green economy context. Applied Energy, 179, 1409-1426. https://doi. org/10.1016/j.apenergy.2016.07.027.

Wargocki, P., Wyon, D. P., Baik, Y. K., Clausen, G., \& Fanger, P. O. (1999). Perceived air quality, sick building syndrome (SBS) symptoms and productivity in an office with two different pollution loads. Indoor Air, 9(3), 165-179. https://doi.org/10.1111/j.1600-0668.1999.t01-1-00003.x.

Wargocki, P., Sundell, J., Bischof, W., Brundrett, G., Fanger, P. O., Gyntelberg, F., et al. (2002). Ventilation and health in nonindustrial indoor environments: report from a European Multidisciplinary Scientific Consensus Meeting (EUROVEN). Indoor Air, 12(2), 113-128. https://doi. org/10.1034/j.1600-0668.2002.01145.x.

Wargocki, P., Wyon, D. P., Sundell, J., Clausen, G., \& Fanger, P. O. (2000). The effects of outdoor air supply rate in an office on perceived air quality, sick building syndrome (SBS) symptoms and productivity. Indoor Air, 10(4), 222-236. https://doi.org/10.1034/j.1600-0668.2000.010004222.x.

Woodroof, E. A., Turner, W. C., Heffington, W., \& Capehart, B. (2012). Energy conservation also yields: capital, operations, recognition and environmental benefits. Energy Engineering, 109(5), 1-14. https://doi. org/10.1080/01998595.2012.10531820.

Yin, R. K. (2014). Case study research: design and methods. London: Sage Publication. 